\title{
EFFECT OF PREVENTATIVE ZINC SUPPLEMENTATION ON DAMAGE TO INTESTINAL INTEGRITY CAUSED BY ESCHERICHIA COLI LIPOPOLYSACCHARIDE ADMINISTRATION: EXPERIMENTAL STUDY IN AN ANIMAL MODEL
}

\author{
Andy Darma ${ }^{1}$, Alpha Fardah Athiyyah ${ }^{1 *}$, Lyly Ekawati Candra ${ }^{1}$, Reza Gunadi Ranuh ${ }^{1}$, \\ Subijanto Marto Sudarmo ${ }^{1}$ \\ ${ }^{I}$ Department of Child Health, Dr. Soetomo Hospital, Faculty of Medicine, Universitas Airlangga, Surabaya, Indonesia \\ *alpha-f-a@fk.unair.ac.id \\ https://doi.org/10.34302/crpjifst/2019.11.5.8 \\ Article history: \\ Received: \\ 9 March 2019 \\ Accepted: \\ 20 September 2019 \\ Keywords: \\ Zinc; \\ Villi length; \\ Enterocyte amount; \\ Intestinal integrity; \\ Lipopolysaccharide;

\section{ABSTRACT} \\ Zinc is widely used as a therapy for gastrointestinal diseases and as a food \\ supplement. Research has suggested beneficial effects of zinc \\ supplementation; however, there is limited knowledge on the effect of zinc \\ on intestinal integrity. The aim of this study to investigate the effect of zinc \\ on damage to the intestinal integrity induced by treatment with Escherichia \\ coli-derived lipopolysaccharide (LPS). Thirty-two male Wistar rats were \\ randomised into eight experimental groups that consumed either a normal \\ diet or zinc-deficient diet, comprising a control group, LPS group (parenteral \\ LPS administration on day 36), zinc group (parenteral zinc administration \\ for 14 days), and zinc + LPS group (parenteral zinc administration for 14 \\ days with additional LPS on day 36). All groups were sacrificed on day 43, \\ and the ileum was removed for histological analysis. The villi length and \\ number of enterocytes were measured on histological slices of the ileum. \\ The results of this study, in the normal diet group treated with LPS, zinc \\ supplementation improved the villi length $(\mathrm{p}<0.0001)$ and enterocyte \\ number $(\mathrm{p}<0.0001)$. Zinc supplementation of rats in the deficient diet group \\ treated with LPS showed improved villi length $(p<0.0001)$ and enterocyte \\ number $(\mathrm{p}<0.0001)$. In rats fed a normal diet, there were significant \\ differences in villi length and enterocyte number in LPS-treated rats \\ compared to those that were not exposed to LPS. In animals fed a zinc- \\ deficient diet and treated with LPS, zinc supplementation improved villi \\ length and enterocyte number.
}

\section{Introduction}

Data indicate that $21 \%$ of the global population suffers from zinc deficiency. This is an important problem worldwide, but especially in developing countries (Brown et al., 2002). Indonesia is a high-risk country for zinc deficiencies, as more than $25 \%$ of the Indonesian population have suffered from zinc deficiencies (Samman, 2007).

In 2004, the World Health Organization (WHO) and UNICEF published guidelines for diarrhoea therapy with zinc and oralit for a period of 10-14 days, where administration of zinc can decrease the incidence of diarrhoea for the next 2-3 months, preventing an estimated $90 \%$ of diarrhoea-related morbidity (WHO/UNICEF, 2004). Zinc is a component of many enzymes that are essential for basic cellular function during all stages of the cell cycle. It is also essential for normal growth (WHO, 2006), as it acts as an antioxidant, improves intestinal absorption (Wapnir, 2000) 
and immune response (Duggan et al., 2002), and also has bactericidal effects (Surjawidjaja et al., 2004). However, the mechanism of zinc to prevent damage to intestinal function and structure induced by lipopolysaccharide (LPS) produced by Escherichia coli infection remains unclear. At present, many zinc supplements are sold as vitamins to aid in prevention; however, research supporting the effect of zinc supplementation on improving intestinal integrity is lacking. This study used LPS derived from $E$. coli serotype O55:B5 as a model of bacterial endotoxin, which was administered at a non-lethal dose that could still generate the expected response. The objectives of the present study were to investigate the effects of zinc on damage to intestinal integrity caused by administration of $E$. coli-derived LPS.

\section{Materials and methods}

\subsection{Samples}

This study received ethical approval from the Animal Care and Use Committee (ACUC) of the Veterinary Medicine School, Airlangga University (Indonesia). Male Wistar rats $(\mathrm{n}=32$, 5 weeks old, approximately $80 \mathrm{~g}$ ) were housed in 16 cages (two per cage), and each cage was supplied with either a zinc-adequate $(30 \mathrm{ppm})$ or a zinc-deficient $(0.5 \mathrm{ppm})$ diet for 6 weeks. Rat were fed according to four dietary treatments, consisting of a normal diet (30 ppm of $\mathrm{ZnSO}_{4}$ ), normal diet with zinc supplementation $(60 \mathrm{ppm}$ of $\left.\mathrm{ZnSO}_{4}\right)$, zinc-deficient diet $(0.5 \mathrm{ppm}$ of $\mathrm{ZnSO}_{4}$ ) or zinc-deficient diet with zinc supplementation (120 ppm of $\mathrm{ZnSO}_{4}$ ), based on a preliminary study conducted by Soemyarso et al. (2019). Zinc supplementation was orally administered through a $\mathrm{ZnSO}_{4}$ solution on day 15 in half of the animals that received the normal diet $(\mathrm{n}=8)$ and half of the zinc-deficient rats ( $\mathrm{n}$ $=8$ ). Rats had ad libitum access to a feed diet containing 0.02-0.04 ppm zinc, and rats were routinely monitored for body weight $(\mathrm{BW})$ and daily intake.
After 5 weeks of the dietary treatments, half of the animals receiving the normal diet $(n=8)$ and the deficiency diet $(\mathrm{n}=8)$ were exposed to oral saline (control), and the other half receiving the normal diet $(\mathrm{n}=8)$ and the deficiency diet ( $\mathrm{n}$ $=8)$ were administered oral LPS $(250 \mu \mathrm{g} / \mathrm{kg} \mathrm{BW}$ in $0.2 \mathrm{ml}$ ) on day 36 to simulate a bacterial challenge. Administration of LPS would induce intestinal distress, similar to other diarrhoea models. One week after the LPS challenge, euthanasia by cervical dislocation was performed for all rats. This study examined the effects of zinc supplementation on intestinal morphology in LPS-challenged rats through the histological evaluation of intestinal tissue sections. Histological analysis of intestinal samples included evaluation of villi length and the number of enterocytes.

\subsection{Small intestine tissue collection}

Tissue sample collection was performed immediately after euthanasia, and blood was collected into heparinised tubes. The small intestine of each rat was dissected into sections of the ileum approximately $3 \mathrm{~cm}$ in length. Each intestinal sample was immediately washed with cold saline and then rinsed with $10 \%$ formalin. The sections were filled with phosphatebuffered formalin solution for $24 \mathrm{~h}$ and then moved to the morphohistology laboratory for histological preparation. Histological preparation of the ileal tissue was carried out through several stages beginning with dehydration, clearing, impregnation, embedding and finally fixation in paraffin. Sections were stained with haematoxylin and eosin and viewed through an Olympus CX 21 microscope under $200 \times$ magnification for villi length assessment and $1000 \times$ magnification to count the number of enterocytes in four areas. The villi length was measured from the tip of the villi to the villous crypt junction. The number of enterocytes was measured by counting the enterocytes per villi. Both villi length and enterocyte amount are expressed relative to the result of the control 
group (normal diet and deficiency diet group). This observation was carried out in the Department of Anatomy and Pathology Dr Soetomo General Hospital and the Faculty of Math and Science at the Universitas Brawijaya Malang.

\subsection{Statistical analysis}

Intestinal morphology was analysed by analysis of variance (ANOVA). All data analyses were performed using SPSS software, version 17. Significance was assessed at $\mathrm{p}<0.05$.

\section{Results and discussions}

Figures $1 \mathrm{~A}-\mathrm{H}$ present the variation in villi length and enterocyte number for each of the eight groups.
Figures $1 \mathrm{~A}-\mathrm{H}$ show the variation in villi length for each group, in addition to enterocytes (black arrows) and damaged cells (red arrows). The difference between the normal diet group (Figure 1A) and the normal diet group with zinc supplementation (Figure 1B) is that the zinc supplementation group had longer villi. Figure $1 \mathrm{C}$ represents the normal diet group treated with LPS, showing blunt villi and multiple damaged epithelial cells, which differs from Figure 1D, representing LPS-treated animals on a normal diet with zinc supplementation, as zinc supplementation ameliorated these negative effects, evidenced by longer villi, fewer damaged cells and more intact epithelium.
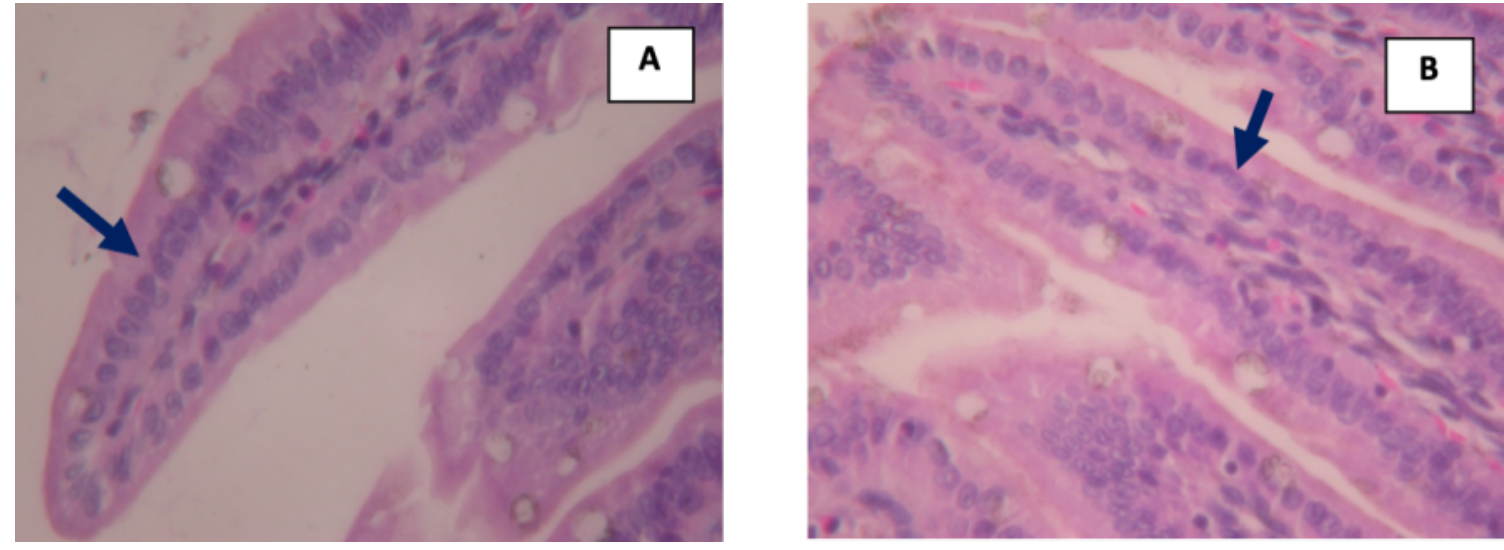

Figure 1A and B. Representative image of the small intestine of rats fed the (A) normal diet and (B) normal diet with zinc supplementation. Enterocytes are indicated by black arrows.
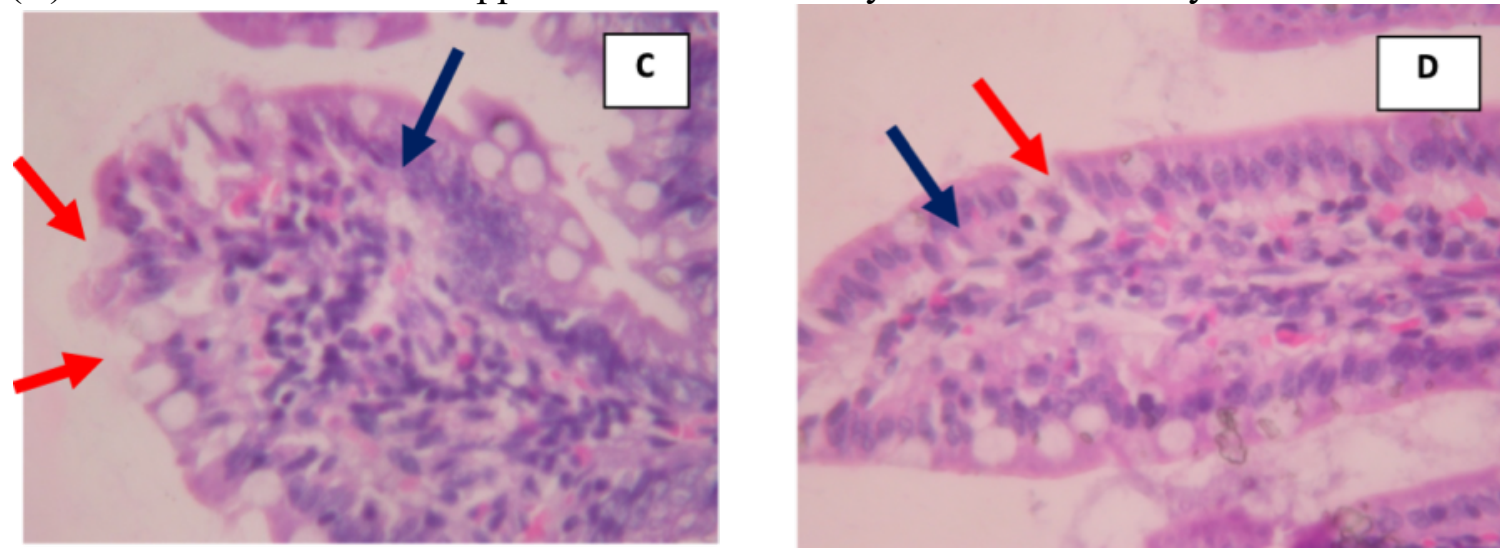

Figure 1C and D. Representative image of the small intestine or rats treated with Escherichia coliderived lipopolysaccharide (LPS) fed the (C) normal diet and (D) normal diet with zinc supplementation. Enterocytes are indicated by black arrows and cell damage is shown by red arrows. 
Figure 1E shows epithelial damage and blunt villi in the group fed the zinc-deficient diet. When zinc-deficient animals were supplemented with zinc (Figure 1F), animals showed longer villi and intact epithelium. Figure $1 \mathrm{G}$ represents the zinc-deficient group treated with LPS, showing blunt villi and damaged epithelial cells. In Figure $1 \mathrm{H}$, animals in the zinc-deficient diet group treated with LPS which received zinc supplementation showed decreased epithelial cell damage. Zinc supplementation in the normal diet group had a protective effect on villi length $(p=0.001)$, while zinc supplementation in deficient animals protected the number of enterocytes $(\mathrm{p}<0.0001)$ and villi length ( $\mathrm{p}<0.0001$; Table 1). Administration of LPS to animals fed a normal diet led to significantly decreased villi length ( $p$
$=0.001)$ and number of enterocytes $(\mathrm{p}<$ 0.0001 ), and zinc-deficient animals showed a decrease in villi length $(\mathrm{p}<0.0001)$ and enterocyte amount $(p<0.0001$; Table 2). Zinc supplementation in both the normal and zincdeficient groups protected the number of enterocytes $(p<0.0001)$ and villi length $(p<$ 0.0001). Zinc supplementation in LPS-treated animals fed a normal diet and deficient diet resulted in improved villi length $(\mathrm{p}<0.0001)$ and number of enterocytes ( $p<0.0001$; Table 3 ). Administration of LPS to animals fed a normal diet and supplemented with zinc led to a decrease in the number of enterocytes, and LPS administration in zinc-deficient animals that had been given zinc supplementation resulted in decreased villi length (Table 4).
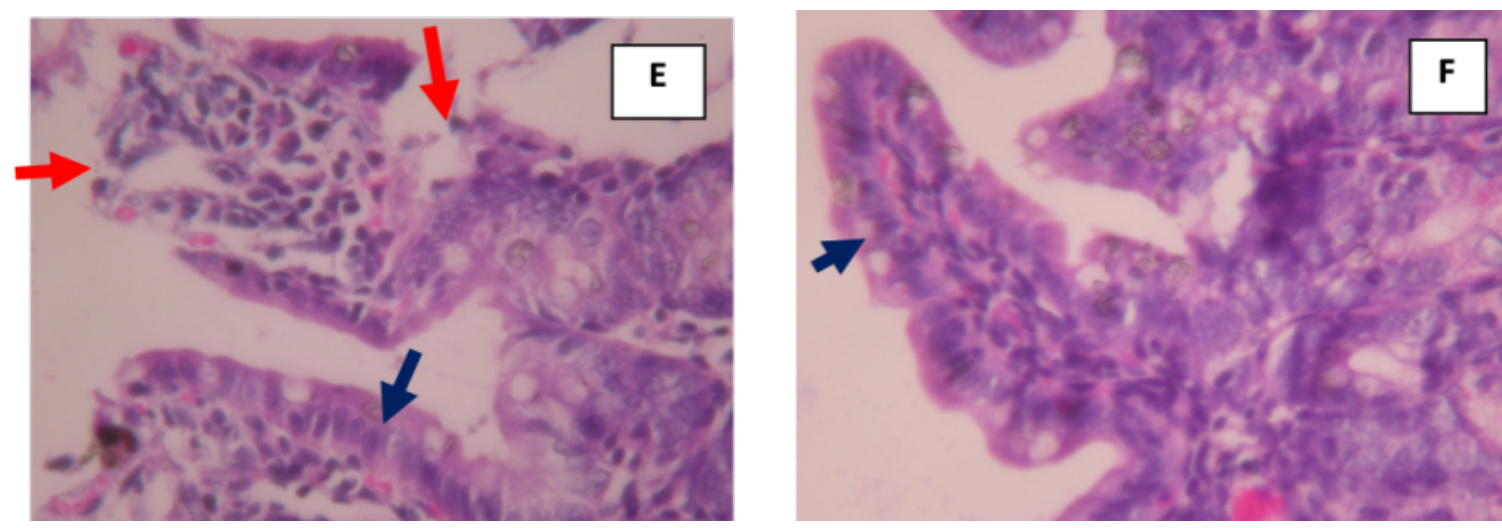

Figure 1E and F. Representative image of the small intestine of rats fed the (E) zinc-deficient diet and (F) zinc-deficient diet with zinc supplementation. Enterocytes are indicated by black arrows and cell damage is shown by red arrows.

The results of this study suggest that zinc supplementation in a normal diet could help to maintain villi length $(\mathrm{p}=0.001)$ and protect against anatomical intestinal damage. In a zincsufficient condition (normal diet), zinc supplementation can improve the endogenous zinc reserve and induce metallothionein synthesis in intestinal cells. This metallothionein could provide anatomical protection against intestinal damage. Higher serum concentrations of zinc are usually associated with increased synthesis of metallothionein in the intestinal mucosa (Martínez et al., 2004; Carlson et al., 2007). Metallothionein is a binding protein that regulates the quantity of zinc absorbed by binding dietary zinc in mucosal cells, thereby controlling its transfer across the basolateral membrane into the circulation, and its subsequent deposition in the liver and intestine (Richards \& Cousins, 1975). 

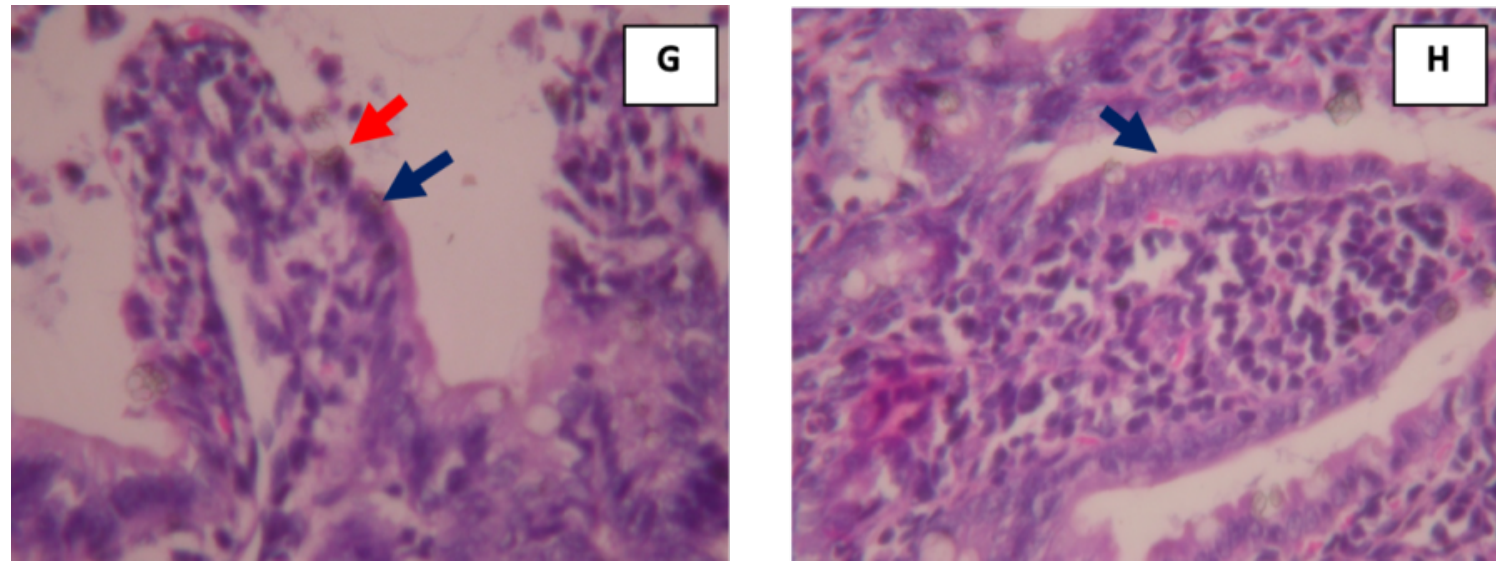

Figure 1G and H. Representative image of the small intestine or rats treated with Escherichia coli-derived lipopolysaccharide (LPS) fed the (G) zinc-deficient diet and (H) zinc-deficient diet with zinc supplementation. Enterocytes are indicated by black arrows and cell damage is shown by red arrows.

Table 1. Different effects of zinc supplementation in normal diet and zinc-deficient diet groups.

\begin{tabular}{|c|c|c|c|c|}
\hline \multirow{2}{*}{ Group } & Villi length $(\mathbf{m m})$ & \multirow{2}{*}{$\mathbf{p}$} & Enterocyte number & \multirow{2}{*}{$\mathbf{p}$} \\
\cline { 2 - 2 } & Mean \pm SD & & Mean \pm SD & \\
\hline Normal diet & $15.095 \pm 0.843$ & $\mathbf{0 . 0 0 1} *$ & $22.187 \pm 1.231$ & $\mathbf{0 . 8 7 1}$ \\
\hline Normal diet + zinc & $21.235 \pm 2.597$ & & $22.312 \pm 0.375$ & \\
\hline Deficient diet & $8.390 \pm 0.388$ & $<\mathbf{0 . 0 0 0 1} *$ & $12.250 \pm 0.540$ & $<\mathbf{0 . 0 0 0 1 *}$ \\
\hline Deficient diet + zinc & $19.640 \pm 0.618$ & & $26.750 \pm 2.131$ & \\
\hline
\end{tabular}

*Significance, $p \leq 0.05$.

Zinc deficiency may enable oxidative damage to the structural integrity of cell membranes, which could alter the function of permeability channels and transport proteins in cell membranes (Hambidge et al., 1986). In the current study, we showed that zinc deficiencies can cause damage to intestinal anatomy and function, and zinc supplementation in deficient animals could protect villi length $(p<0.0001)$ and the number of enterocytes $(\mathrm{p}<0.0001)$. Thus, in conditions of deficiency, zinc supplementation could protect against anatomical and functional intestine damage.

Table 2. Different effects of lipopolysaccharide (LPS) administration in normal diet and zincdeficient diet groups.

\begin{tabular}{|c|c|c|c|c|}
\hline \multirow{2}{*}{ Group } & Villi length (mm) & \multirow[t]{2}{*}{ p } & Enterocyte number & \multirow[t]{2}{*}{$\mathbf{p}$} \\
\hline & Mean + SD & & Mean + SD & \\
\hline Normal diet & $15.095+0.843$ & $0.001 *$ & $22.187+1.231$ & $<0.0001 *$ \\
\hline Normal diet + LPS & $9.095+1.566$ & & $10.000+0.204$ & \\
\hline Deficient diet & $8.390+0.388$ & $<0.0001 *$ & $12.250+0.540$ & $<0.0001 *$ \\
\hline Deficient diet + LPS & $6.095+0.495$ & & $5.375+1.050$ & \\
\hline
\end{tabular}

*Significance, $p \leq 0.05$.

Damage to the intestinal mucosal epithelium is a characteristic feature of numerous gastrointestinal diseases such as infectious diarrhoea or inflammatory bowel 
diseases. The intestinal epithelium has enormous regenerative capabilities that allow rapid healing after damage. Firstly, cells beneath the damaged epithelial surface migrate into the wound within minutes to hours to seal the denuded area, a process that has been termed epithelial restitution. Secondly, cells proliferate to replenish the reduced cell pool. Finally, epithelial cells differentiate to mature enterocytes with diverse functional abilities within the intestinal epithelium (Goke \& Podolsky, 1996).

The LPS challenge in rats fed a normal diet affected the villi length $(p=0.001)$ and enterocyte number $(\mathrm{p}<0.0001)$, which was also observed in the zinc-deficient group, affecting villi length $(p<0.0001)$ and enterocyte number $(\mathrm{p}<0.0010)$. Administration of LPS derived from $E$. coli in normal diet groups and deficient groups was found to destroy intestinal integrity, evidenced by decreases in villi length and enterocyte number. This experiment demonstrates that an oral LPS challenge is sufficient to induce intestinal inflammation. Excessive inflammation in the intestine may reduce the enterocyte barrier function, allowing additional bacterial and inflammatory challenges to occur. An adequate zinc status prevents barrier disruption in the enterocyte monolayer, as well as bacterial adhesion and internalization. Serum zinc status should be influenced to show positive developmental changes to intestinal integrity and immune function during the suckling period and after weaning. In this context, dietary supplementation with $3000 \mathrm{mg} / \mathrm{kg}$ zinc oxide was previously found to reduce the incidence of LPS-induced translocation of $E$. coli into mesenteric lymph nodes (Huang et al., 1999), and it also improved small intestinal mucosal epithelial morphology in recently weaned pigs (Li et al., 2001). Administration of LPS results in ischemia and destroys mature cells, and can also disrupt the growth and maturation of immature cells (Ruemmele, 2007). LPS derived from $E$. coli of an enteropathogenic serotype can be used as a pathogen because this endotoxin determines the innate immune response (Andonova et al., 2001) and increases bacterial translocation in the intestine (Huang et al., 1999).

Table 3. Different effects of lipopolysaccharide (LPS) administration and zinc supplementation in normal diet and zinc-deficient diet groups.

\begin{tabular}{|c|c|c|c|c|}
\hline \multirow{2}{*}{ Group } & Villi length $(\mathbf{m m})$ & \multirow{2}{*}{$\mathbf{p}$} & Enterocyte number & \multirow{2}{*}{$\mathbf{p}$} \\
\cline { 2 - 2 } & Mean $\mathbf{\text { SD }}$ & & Mean \pm SD & \\
\hline Normal diet + zinc + LPS & $15.562 \pm 2.016$ & $\mathbf{0 . 0 0 1 *}$ & $18.375 \pm 1.689$ & $<\mathbf{0 . 0 0 0 1 ^ { * }}$ \\
\hline Normal diet + zinc & $21.235 \pm 2.597$ & & $22.312 \pm 0.375$ & \\
\hline Deficient diet + zinc + LPS & $13.737 \pm 0.739$ & $<\mathbf{0 . 0 0 0 1} *$ & $12.750 \pm 1.513$ & $<\mathbf{0 . 0 0 0 1 *}$ \\
\hline Deficient diet + zinc & $19.640 \pm 0.618$ & & $26.750 \pm 2.131$ & \\
\hline
\end{tabular}

*Significance, $p \leq 0.05$.

Zinc has been implicated in diarrhoea due to its effect on intestinal mucosal permeability (Rodriguez et al., 1996), and dietary zinc can help prevent or alleviate intestinal diseases. At pharmacological levels, this effect may be due to the antimicrobial properties of zinc (Owusu-Asiedu et al., 2003) and disruption of bacterial-enterocyte binding, as well as subsequent bacterial translocation (Huang et al., 1999).
We found that zinc supplementation in LPStreated rats fed a normal diet or deficient diet helped to prevent damage to the intestine anatomy and function. Thus, zinc supplementation in the normal diet group and deficient diet group infected by LPS protected the intestinal integrity, showing improved villi length $(p<0.0001)$ and number of enterocytes $(\mathrm{p}<0.0001)$. This study also demonstrated that zinc supplementation in rats in the group fed a normal diet with LPS treatment protected the 
number of enterocytes $(p<0.0001)$, and zinc supplementation in the deficient diet group treatment with LPS protected villi length $(\mathrm{p}<$ $0.0001)$ and the number of enterocytes $(\mathrm{p}<$ $0.0001)$. LPS administration in rats fed a normal diet and provided zinc supplementation before only destroyed intestine function because anatomical structure had not yet been disrupted. There was likely a decrease in intestinal function due to the increased number of immature enterocytes, which were not yet functioning optimally. Immature enterocytes were increased due to the increased cell proliferation. Administration of LPS in deficient animals that had been given zinc supplementation showed a destroyed intestinal anatomical structure, but the function was not disrupted.

Table 4. Different effects of lipopolysaccharide (LPS) administration and zinc supplementation in normal diet and zinc-deficient diet groups.

\begin{tabular}{|c|c|c|c|c|}
\hline \multirow{2}{*}{ Group } & Villi length (mm) & \multirow[t]{2}{*}{$\mathbf{p}$} & Enterocyte number & \multirow[t]{2}{*}{$\mathbf{p}$} \\
\hline & Mean + SD & & Mean + SD & \\
\hline Normal diet + zinc + LPS & $15.562+2.016$ & $<0.0001 *$ & $18.375+1.689$ & $<0.0001 *$ \\
\hline Normal diet + LPS & $9.095 \pm 1.566$ & & $10.000+0.204$ & \\
\hline Deficient diet + zinc + LPS & $13.737+0.739$ & $<0.0001 *$ & $12.750+1.513$ & $<0.0001 *$ \\
\hline Deficient diet + LPS & $6.095 \pm 0.495$ & & $5.375 \pm 1.050$ & \\
\hline
\end{tabular}

*Significance, $p \leq 0.05$.

In general, measurements of villus height and crypt depth provide an indication of the maturity and functional capacity of enterocytes (Roselli, 2003). Considering the role of zinc in RNA and DNA synthesis, these increases may be explained by an increase in cell proliferation and protein synthesis promoted by supplementary zinc (Hampson, 1986). Dietary zinc supplementation was found to exert a beneficial effect on intestinal morphology through increasing IGF-I expression in the small intestinal mucosa, which results in increased mucosal growth, brush border activity and nutrient absorption (Tako et al., 2005; Carlson et al., 2004). This is in agreement with other studies that reported no differences in the villus height and crypt depth of weaned pigs fed diets supplemented with zinc oxide (Li et al., 2006).

Enterocyte renewal in LPS-challenged rats might have been increased to maintain intestinal integrity in order to prevent bacteria from crossing the mucosal epithelial barrier. There is a relationship between intestinal architecture and the prevention of diarrhoea, as increased villus height and shorter crypt depth may have a higher absorption capacity and a lower rate of secretion from secretory cells, thereby helping to prevent diarrhoea (Namkung et al., 2006).

It is generally known that a lack of zinc may impair DNA synthesis and therefore decrease cell division and proliferation (Nabuur et al., 1993). Others have shown that zinc may promote the repair of wounded monolayers of cultured vascular endothelial cells through the lipo-oxygenase pathway via fibroblast growth factor signalling (Williams, 1989). Additionally, intracellular zinc may regulate various metalloproteins, transcription factors and other ligands in the intestinal epithelium. Thus, zinc may initiate several intracellular signal transduction pathways that directly or indirectly enhance cell migration. The effects of zinc on epithelial cell restitution in vitro are not as potent as the effects described previously for various cytokines and growth factors, for example TGF-alpha, epidermal growth factor, interferon-gamma and interleukin-1 beta, which were found to induce 2.3-5.5-fold enhancement of IEC-6 cell restitution in vitro (Kaji et al., 1994). 
The protective role of zinc on resisting intestinal disease is well known (Brown et al., 2002). Zinc plays an important role in maintaining membrane function and stability. Some researchers suggest that the mechanism of this activity involves the stabilisation of the membrane structure. The integrity of this intestinal barrier is fundamental to epithelial cells (Cario, 2000). Zinc plays a role in maintaining epithelial barrier integrity and function (Lu \& Walker, 2001).

Zinc oxide has been shown to improve gastrointestinal tract function by increasing mucosal thickness, villi height and width of the small intestine (Li et al., 2001). Zinc primarily affects tissues with a high turnover rate, such as those of the gastrointestinal tract and immune system. Zinc is needed in these tissues for DNA and protein synthesis. Zinc stabilises the membrane structure and may modify membrane function, protect membranes from the effects of infectious agents, and may act at the tight junction to prevent the increased intestinal permeability associated with malnutrition or tumour necrosis factor. Zinc may also stimulate immune defences while minimising the adverse effect of immune cell activation by bacterial translocation on the epithelial layer (Huang et al., 1999).

\section{Conclusions}

Zinc supplementation led to improved villi length in animals fed a normal diet, and improved the villi length and enterocyte number in rats fed a zinc-deficient diet. In rats fed a normal diet, there were significant differences in villi length and enterocyte number in LPStreated rats compared to those that were not exposed to LPS. In animals fed a zinc-deficient diet and treated with LPS, zinc supplementation improved villi length and enterocyte number.

\section{References}

Andonova, M., Borissov, I., Sotirov, L. (2001). Changes in some factors of the innate immunity and serum zinc and iron concentrations in pigs following intravenous administration of Escherichia coli lipopolysaccharide. The Onderstepoort Journal of Veterinary Research, 68, 91-99.

Brown, K.H., Peerson, J.M., Rivera, L, et al. (2004). Effect of supplemental zinc on the growth and serum zinc concentrations of prepubertal children: a meta-analysis of randomized controlled trials. The American Journal of Clinical Nutrition, 75, 1062-1071. Cario, E. (2000). Effect of exogenous zinc supplementation on intestinal epithelial repair in vitro. European Journal of Clinical Investigation, 30(3), 419-428.

Carlson, D., Beattie, J.H., Poulsen, H.D. (2007). Assessment of zinc and copper status in weaned piglets in relation to dietary zinc and copper supply. Journal of Animal Physiology and Animal Nutrition, 91, 19-28.

Carlson, D., Poulsen, H.D., Vestergaard, M. (2004). Additional dietary zinc for weaning piglets is associated with elevated concentrations of serum IGF-I. Journal of Animal Physiology and Animal Nutrition, 88, 332-339.

Duggan, C., Gannon, J., Walker, W.A. (2002). Protective nutrients and functional foods for the gastrointestinal tract. The American Journal of Clinical Nutrition, 75, 789-808.

Goke, M., Podolsky, D.K. (1996). Regulation of the mucosal epithelial barrier. Bailliere's Clinical Gastroenterology, 10, 393-405.

Hambidge, K.M., Casey, C.E., Kreb, N.F. (1986). Zinc. In: W. Mertz (Ed.), Trace Elements in Human and Animal Nutrition. (pp. 1-137), Orlando, FL: Academic Press Inc..

Hampson, D.J. (1986). Alterations in piglet small intestinal structure at weaning. Research in Veterinary Science, 40, 32-40.

Huang, S.X., McFall, M., Cegielski, A.C., Kirkwood, R.N. (1999). Effect of dietary zinc supplementation on Escherichia coli septicemia in weaned pigs. Swine Health Product, 7, 109-111.

Kaji, T., Fujiwara, Y., Yamamoto, C., Sakamoto, M., Kozuka, H. (1994). Stimulation by zinc of cultured vascular endothelial cell proliferation: possible involvement of endogenous basic fibroblast 
growth factor. Life Sciences, 55, 1781-1787.

Li, B.T., Van Kessel, A.G., Caine, W.R., Huang, S.X., Kirkwood, R.N. (2001). Small intestinal morphology and bacterial populations in ileal digesta and feces of newly weaned pigs receiving a high dietary level of zinc oxide. Canadian Journal of Animal Science, 81, 511-516.

Li, X., Yin, J., Li, D., Chen, X., Zang, J., Zhou, X. (2006). Dietary supplementation with zinc oxide increases IGF-I and IGF-I receptor gene expression in the small intestine of weanling piglets. The Journal of Nutrition, 136, 1786-1791.

Lu, L., Walker, W.A. (2001). Pathologic and physiologic interactions of bacteria with the gastrointestinal epithelium. The American Journal of Clinical Nutrition, 73, 1124S$1130 \mathrm{~S}$.

Martínez, M.M., Hil, G.M., Link, J.E., Raney, N.E., Tempelman, R.J., Ernst, C.W. (2004). Pharmacological zinc and phytase supplementation enhance metallothionein mRNA abundance and protein concentration in newly weaned pigs. The Journal of Nutrition, 134, 538-544.

Nabuur, M.J.A., Hoogendoo, A., Molen, E.J., Osta, A.L.M. (1993). Villus height and crypt depth in weaned and unweaned pigs, reared under various circumstances in the Netherlands. Research in Veterinary Science, $55,78-84$.

Namkung, H., Gong, J., Yu, H., de Lange, C.F.M. (2006). Effect of pharmacological intakes of zinc and copper on growth performance, circulating cytokines and gut microbiota of newly weaned piglets challenged with coliform lipopolysaccharides. Canadian Journal of Animal Science, 86, 511-522.

Owusu-Asiedu, A., Nyachoti, C.M., Marquardt, R.R. (2003). Response of earlyweaned pigs to an enterotoxigenic Escherichia coli (K88) challenge when fed diets containing spraydried porcine plasma or pea protein isolate plus egg yolk antibody, zinc oxide, fumaric acid, or antibiotic. Journal of Animal Science, 81, 1790-1798.
Richards, M.P., Cousins, R.J. (1975). Mammalian zinc homeostasis: requirement for RNA and metallothionein synthesis. Biochemical and Biophysical Researsch Communications, 64, 1215-1223

Rodriguez, P., Darmon, N., Chappuis, P., Candalh, C., Blaton, M.A., Bouchaud, C., et al. (1996). Intestinal paracellular permeability during malnutrition in guinea pigs: effect of high dietary zinc. Gut, 39, 416-422.

Roselli, M., Finamore, A., Garaguso, I., Britti, M.S., Mengheri, E. (2003). Zinc oxide protects cultured enterocytes from the damage induced by Escherichia coli. The Journal of Nutrition, 133, 4077-4082.

Ruemmele, F.M. (2007). Chronic enteropathy: molecular basis. Nestle Nutrition Workshop Series Paediatric Programme, 59, 73-85.

Samman, S. (2007). Zinc. Nutrition \& Dietetics, 64(4), S131-S134.

Soemyarso, N.A., Prasetyo, R.V., Kurniawan, M.R., Noviandi, R., Darma, A., Athiyyah, A.F., et al. (2019). Role of zinc in the innate and adaptive immunity of the bladder mucosa. Accepted for publication.

Surjawidjaja, J.E., Hidayat, A., Lesmana, M. (2004). Growth inhibition of enteric pathogens by zinc sulfate: an in vitro study. Medical Principles and Practice, 13, 286289.

Tako, E., Ferket, P.R., Uni, Z. (2005). Changes in chicken intestinal zinc exporter mRNA expression and small intestinal functionality following intra-amniotic zinc methionine administration. The Journal of Nutritional Biochemistry, 16, 339-346.

Wapnir, R.A. (2000). Zinc deficiency, malnutrition and the gastrointestinal tract. The Journal of Nutrition, 130, 1388S-1392S. World Health Organization (2006). Implementing the new recommendations on the clinical management of diarrhea: guidelines for policy makers and program managers. Available from: whqlibdoc.who.int/ publications/2006/ 9241594217.

Williams, R.J.P. (1989). An introduction to the 
biochemistry of zinc. In: C.F. Mills (Ed.), Zinc in Human Biology. (pp. 15-31), London-Berlin- Heidelberg: Springer.

World Health Organization, UNICEF (2004). WHO/UNICEF joint statement: clinical management of acute diarrhea. New York: The United Nations Children's Fund/World Health Organization.

\section{Acknowledgment}

The authors thank all the teams who worked on this study. 